\title{
An Information Content Measurement Model of the Implementation Factors in E-commerce
}

\author{
Peng Jinshuan, Xu Lei and Zhou Xiaoxiang \\ Chongqing Key Lab of Traffic System \& Safety in Mountain Cities, Chongqing \\ Jiaotong University, Chongqing 400074, China \\ pengjinshuan@163.com,37951759@qq.com,393983361@qq.com
}

\begin{abstract}
In this study, aiming at the influences brought by multiple factors in implementation process, the factors that lead to successful e-commerce are analyzed, and an information content measurement model of implementation factors in e-commerce based on information axiom is put forward. This model firstly analyzes the factors that/influence the implementation process in e-commerce, and proposes the factors of successful implementation based upon independence of information. Then by building different information content measurement models, the overall information content of the implementation process in e-commence could be obtained. Va the information content, the judgment whether an e-commence is successul dan be realized. Finally, the validity of the model is verified via application example.

Keywords: e-commerce; implementation factons information content; measurement model

\section{Introduction}

E-commerce is the mos important field in information revolution with the widest influence to the whole society, and it has great impact on operation mode of social economic activities, efficiency of economic activities and changes of social economic environment [1-3], Given opportunities and challenges brought by economic globalization how to enhance international competitiveness and achieve sound and rapid development by laking advantage of e-commerce has drawn wide attention of national governments enterprises and academic circle. Implementation effects of ecommerce and evaluation analysis have been a key technology and research hotspot in study of e-commerce.

By far, some researches and analysis have been conducted and corresponding results were achieved. Delone and Mclean summed up a classical model on success evaluation of information systems consisting of six main dimensions, namely system quality, information quality, system use, user satisfaction, individual impact and organizational impact, later they improved this model and added impact analysis of service quality to it [4-6]. According to Seddon, system quality directly influenced perceived usefulness and user satisfaction, and perceived usefulness was the key factor of user satisfaction. Based upon that, information success model of Seddon was put forward [7-8]. Wu \& Wang put forward an knowledge management system (KMS) success model, system quality, information quality, perceive benefit of knowledge management system, user satisfaction and system use were determined to evaluate the KMS [9].
\end{abstract}


Based on existing researches, we try to analyze implementation effects from the aspect of the information content of implementation factors in e-commence, which can make a comprehensive analysis to implementation factors of e-commence from the aspects of integrality and completeness.

\section{Basic Principles of Information Axiom}

Axiomatic design was put forward by Dr. Suh of MIT in 1990. It is a specific application of Shannon's information law in the design filed, which is an effective method in providing a design and analysis tool for the analysis and measurement of information content in e-commence. Independence axiom and information axiom are its two vital important principles [10-13].

\subsection{Independence Axiom}

During an acceptable design decision, in the mapping process of design parameters of adjacent domain, the design parameter should not influence each other, namely each design parameter should be independent. And the corresponding design matrix manifests as diagonal matrix or triangular matrix. The process of measurement and analysis on the information content of the implementation factors in e-commence should ensure that the mapping relation between any two domains of measurement factors keeps their independence.

\subsection{Information Axiom}

In the process of measurement and analysis on information content of implementation factors in e-commence, on the premise that the mapping relation between any two domains of measurement factors is independent, the optimal designing scheme is the one that contains the least information content. Information content $I_{i}$ is determined by the $\log$ function that fulfills the probability of design parameters requirements of implementation measurement factor domain in a certain e-commence. It can be expressed as

$$
\text { O } I C_{i} \rightleftharpoons \log _{2} F_{i}=\log _{2}\left(1 / F_{i}\right)
$$

where, $F_{i}$ is the probability that fulfills the requirements of design parameters of implementation measurement factors domain in a certain e-commence.

It needs to be noted that if the design parameter of factor domain of implementation measurement in e-commence is required to be continuous random variables, the corresponding probability density function $\rho_{v}(D P)$ generally distributes at random. Thus, the probability $F_{i}$ that fulfills the requirement to design parameters of implementation measurement factor domains in e-commence can be expressed as:

$$
F_{i}=\int_{b_{i}}^{a_{i}} \rho_{v}(D P) d D P=\rho_{i}
$$

where, $a_{i}$ and $b_{i}$ respectively represent the upper limit and lower limit of the probability of design parameter of implementation measurement factor domain in e-commence.

In the implementation process of e-commence influenced by various factors, the probability $F_{i}$ that fulfills requirements of design parameters of implementation measurement factor domain can be obtained via the overlapping scope $G_{i}$ between design scope $D_{i}$ and 
system scope $S_{i}$, that is to be obtained from the only region that fulfills the requirement of design parameter. Thus, formula (1) can be transformed to:

$$
\Psi_{i}=-\log _{2} F_{i}=\log _{2}\left(1 / F_{i}\right)=\log _{2}\left(S_{i} / G_{i}\right)
$$

According to axiomatic design theory, in the measurement and analysis process of the information content of implementation factors in e-commence, firstly the implementation factors in e-commence should be kept independent based on independence axiom, secondly the soundest designing scheme should be selected among feasible plans based upon information axiom.

\section{Implementation Factors and Evaluation System of E-commence}

Clearly definition of successful implementation of a certain e-business is the precondition of the research on how to run an e-business smoothly. The successful implementation of e-commence is a multi-dimensional and relative concept. It is multidimensional just because evaluation of single index cannot fully describe the implementation effect of an e-business; it is relative because whether ane-commence is successful is largely decided by the evaluation mode or standard to some extent.

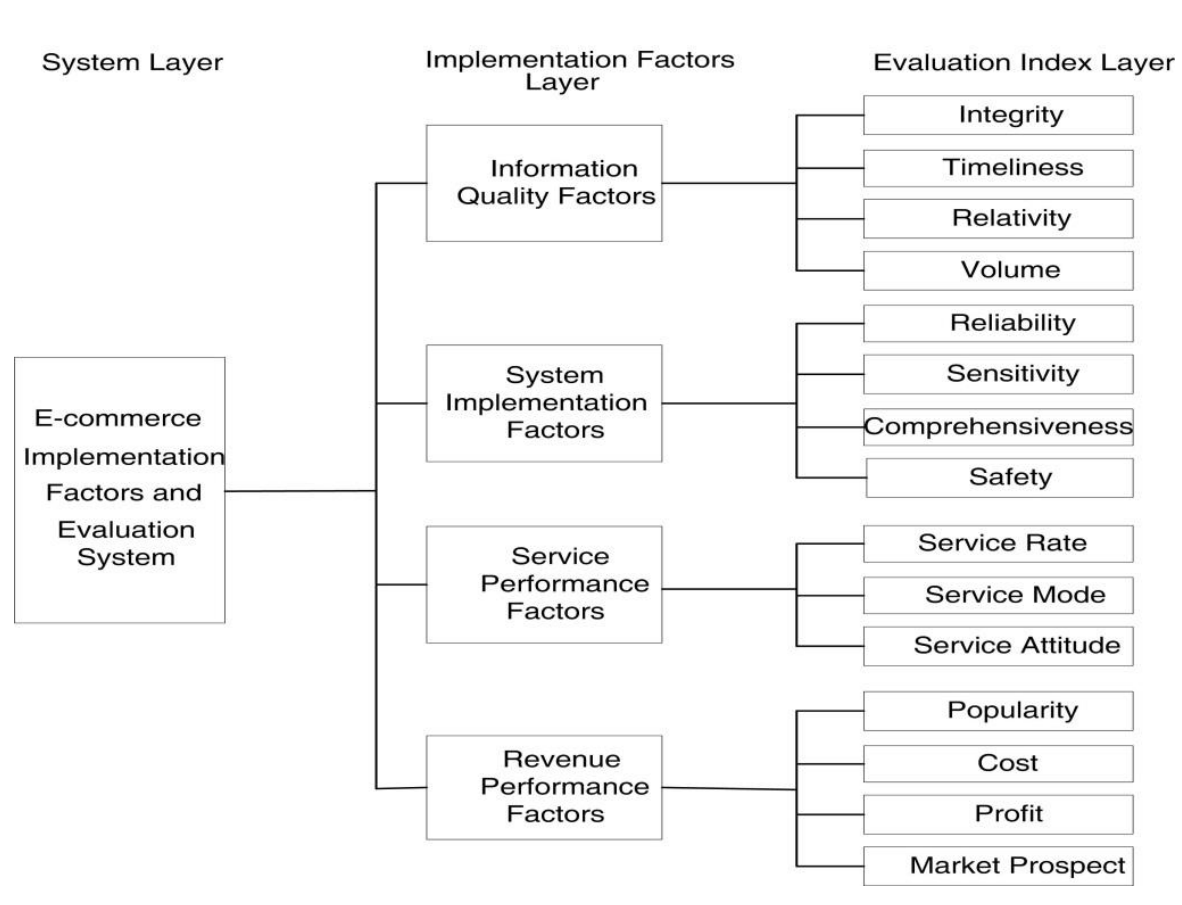

Figure 1. Implementation Factors and Evaluation System of E-commence

In this paper, the evaluation model of successful e-commence of Delone \& Mclean is selected as the basic framework, and made some adjustment to concrete items in each kind of factors by combining studies in other documents and the current development of e-commence of the enterprises, and build implementation factors and corresponding evaluation system of e-commence on the basis of satisfying the independence axiom in this paper.

Modified implementation factors of e-commence may be analyzed via four aspects, namely the information quality, system implementation, service performance and 
revenue performance of e-commence. Then by combining various analytical methods including questionnaire inquiry and expert consultation, corresponding evaluation index system of implementation factors in e-commence can be obtained based upon the independence analysis. The concrete structure is shown in Figure 1.

\section{Information Content Measurement of Implementation Factors}

The methods of calculating information content vary in different evaluation index. The formula for information content calculation of Dr. Suh is suit for manufacturing system, however, cannot be applied to general decision making system. Thus, in this paper, the evaluation index system of implementation factors in e-commence will be set as an example for discussing the calculation method of information content.

\subsection{Information Quality Evaluation Index}

Information quality embodies the implementation performance of e-commence. The higher is the information quality, the smaller the information côntent is in the system.

4.1.1. Information Content of Integrity: Integrity of implementation/information of ecommence can be measured by integrity $R_{I N T}$. In the implementation phase of ecommence, integrity of information is a fuzzy-concept and can only expressed in fuzzy language. Thus, fuzzy language should firstly be transfomed as continuous numbers $f\left(R_{I N T}\right)$ in interval $[0,1]$ to express the evaluation value. The evaluation value can be obtained via expert consolation or statistic analysis. When $f\left(R_{I N T}\right)=1$, the information integrality is the best, and the information content is 0 . The calculation formula of the information content of integrity is as following:

$$
I C\left(R_{T}\right)=\log _{2}
$$

where, IC $\left(R_{I N T}\right)$ Tepresents information content of integrity, $f\left(R_{I N T}\right)$ represents the integrity function, and $e$ is the nat ral constant.

4.1.2. Info-mation Content of Relativity: The relativity of implementation information of e-commence can be measured by $R_{R E L}$, which contains actual information search releyancy $R_{R E L-r}$ and demanded information search relevancy $R_{R E L-o}$. The smaller the error is between actual information search and demanded information search, the higher the relevancy is, however the smaller the information content will be. When $R_{R E}=1$, the information content is 0 . Thus, the calculation formula of the information content of relevancy can be expressed as:

$$
I C\left(R_{R E L}\right)=\log _{2} e^{\left|R_{R E L-o}-R_{R E L-r}\right|}
$$

4.1.3. Information Content of Timeliness: The timeliness of implementation information of e-commence can be measured by rate of timeliness $R_{T I M}$. The higher is the timeliness $R_{T I M}$, the smaller information content. When $R_{T I M}=1$, information content is 0 . Thus, the formula of information content of timeliness can be calculated as following:

$$
I C\left(R_{T I M}\right)=\log _{2} e^{1-R_{T M}}
$$


4.1.4. Information Content of Volume: The volume of implementation information of ecommence can be measured as rate of volume $R_{V O L}$. It is a qualitative concept because it reflects the volume and capacity of information in an e-commence system. Thus, it should be described with fuzzy language. So firstly fuzzy language should be transformed as continuous numbers $u\left(R_{\text {VOL }}\right)$ in the interval $[0,1]$, to express the value of evaluation. The value of evaluation can be obtained via expert consultation and statistical analysis. The higher is the volume, the smaller the information content will be. When $u\left(R_{V O L}\right)=1$, the information content should be 0 . Thus, the computational formula of the information content of volume can be expressed as:

$$
I C\left(R_{V O L}\right)=\log _{2} e^{1-u\left(R_{V O L}\right)}
$$

\subsection{System implementation Evaluation Index}

4.2.1. Information Content of Reliability: Implementation information riability of ecommence can be measured as degree of reliability $R_{R E L}$. The highe is the degree of reliability, the smaller the information content will be. When $R_{R} L_{L}=1$, information content is 0 . Thus, the computational formula of information content of degree of reliability can be expressed as:

$$
I C\left(R_{R E L}\right)=\log _{2} e^{1-R_{R E L}}
$$

4.2.2. Information Content of Sensitivitys The sensitivity of implementation information of e-commence can be measured as sensitivity $R_{S E N}$ (The higher is the degree of sensitivity, the smaller the information content wilpe. When $R_{S E N}=1$, information content is 0 . Thus, the computational formula of information content of sensitivity is as following:

$$
I C\left(R_{S E N}\right)=\operatorname{Og}_{0} e^{1-R_{S E N}}
$$

4.2.3. Information Content of Comprehensiveness: The information content of comprehensiyeness of e-commencecan be measured as information coverage rate $R_{\text {сом }}$. It is a qualitative concept because it reflects the capacity of covering information in an ecommence system. Thus, it should be described with fuzzy language, then transformed as continuous numbers $u\left(R_{m}\right)$ in the interval $[0,1]$. The value of evaluation can be obtained via expert consultation and statistical analysis. The computational formula of the information content of comprehensiveness can be obtained as following:

$$
\int C\left(R_{\text {COM }}\right)=\log _{2} e^{1-v\left(R_{\text {COM }}\right)}
$$

4.2.4. Information Content of Safety: The safety of implementation information of ecommence can be measured as degree of safety $R_{S A F}$. The degree of safety is a qualitative concept because it reflects the capacity of security in an e-commence system. Thus, it should be described with fuzzy language, then transformed as continuous numbers $\gamma\left(R_{S A F}\right)$ in the interval $[0,1]$ to express the value of evaluation. The computational formula of the information content of degree of security is as follows:

$$
I C\left(R_{S A F}\right)=\log _{2} e^{1-\gamma\left(R_{S A F}\right)}
$$




\subsection{Service Performance Evaluation Index}

The information content of service performance includes three sub-modules, namely the service rate, service mode, and service attitude. The service system of e-commence has caused wide attention among users, and is an important index in the evaluation of the system performance. The higher is the evaluation of users, the smaller the information content will be. Thus, information content of service rate, service mode and service attitude need to be calculated via questionnaire inquiry or consulting relative specialists and obtain an interval $[0,1]$ to express corresponding evaluation values. Supposing that the statistical value of service rate, service mode and service attitude are defined as $K\left(R_{S-R A T}\right), K\left(R_{S-M O D}\right), K\left(R_{S-A T T}\right)$, respectively. Then the information content of service performance can be calculated as:

$$
\begin{aligned}
& I C\left(R_{S-R A T}\right)=\log _{2} e^{1-K\left(R_{S-R A T}\right)} \\
& I C\left(R_{S-M O D}\right)=\log _{2} e^{1-K\left(R_{S-M O D}\right)} \\
& I C\left(R_{S-A T T}\right)=\log _{2} e^{1-K\left(R_{S-A T T}\right)}
\end{aligned}
$$

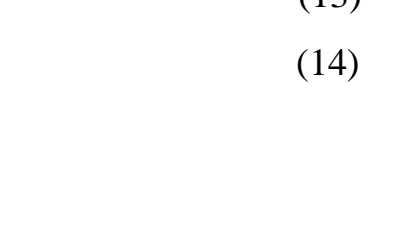

\subsection{Revenue Performance Evaluation Index}

4.4.1. Information Content of Popularity: The popularity of implementation information of e-commence may be measured as customer approval rating $R_{P O P}$, the parameter need to be obtained via analytical analysis based on questionnaire inquiry. When $R_{P O P}=1$, information content is 0 . Thus, the computational formula of information content of popularity may be expressed as:

$$
I C\left(R_{P O P}\right)=\log _{2} e^{1-R_{P O P}}
$$

4.4.2. Information Content of Cost: The cost of implementation information of ecommence can be measured as the cost value $R_{\text {cos }}$. The lower is the cost value, the smaller the information content will be. When $R_{\cos }=0$, information content is 0 . Thus, the information content of cost can be calculated as:

$$
\text { IC }\left(R_{C O S}\right)=\log (e \text { SoS }
$$

4.4.3. Information Content of Profit: The profit of implementation information of ecommence can be measured as profit rate $R_{P R O}$. The higher is the profit rate, the smaller the information cóntent will be. When $R_{P R O}=1$, information content is 0 . Information content of profit can be expressed as:

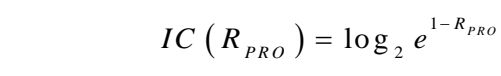

4.4.4 Information Content of Market Prospect: The market prospect of implementation information of e-commence can be measured as market generalization rate $R_{\text {MAR }}$, and it needs to be obtained by consulting relative specialists and obtain a qualitative expression of membership degree $\eta\left(R_{\text {MAR }}\right)$. The higher is the market generalization rate, the smaller the information content will be. When $R_{\text {MAR }}=1$, information content is 0 . Thus, the computational formula of information content of market prospect can be expressed as: 


$$
I C\left(R_{\text {MAR }}\right)=\log _{2} e^{1-\eta\left(R_{M A R}\right)}
$$

\section{Measurement Model and Algorithm Implementation}

According to the evaluation index system of implementation factors in e-commence, the information content of a certain e-business can be expressed with information matrix:

$$
I C=\left(I C_{I Q F}, I C_{S I F}, I C_{S P F}, I C_{R P F}\right)
$$

In this formula, $I C_{I Q F}, I C_{S I F}, I C_{S P F}, I C_{R P F}$ respectively stand for information content of information quality, system implementation, service performance and revenue performance. And in the process of conducting each implementation factor and evaluation index, information in the same category satisfy independence axiom, thus, the information content can mathematically add and subtract with each other directly. As for information in different categories, due to their different relative importance in assessment process, weighted approach should be applied.

Respectively set the weights of information content of the information quality, system implementation, service performance and revenue performance as $W_{\text {SFF }}, W_{S I F}, W_{S P F}, W_{R P F}$, and the total information content of implementation factors of e-commence can be defined as:

$$
I C=W_{I Q F} * I C_{I Q F}+W_{S I F} * I C_{S I F}+W_{S P F} * I C_{S P F}+W_{R P F} * I C_{R P F}
$$

In the formula, the evaluation inde value of each implementation factor fulfills the following relation:

$$
\left\{\begin{array}{l}
I C_{I Q F}=I C\left(R_{I N T}\right)+I C\left(R_{\text {REL }}\right)+I C\left(R_{T I M}\right)+C g\left(R_{V O L}\right) \\
I C_{S I F}=I C\left(R_{R E L}\right)+I C\left(R_{S E N}\right)+I C\left(R_{C O M}\right)+I C\left(R_{S A F}\right) \\
I C_{S P F}=I C\left(R_{S-A A T}+I C\left(R_{S-M O D}\right)+I C\left(R_{S-A T T}\right)\right. \\
I C_{R P F}=I C\left(R_{P O R}\right)+I C\left(R_{C O S}+I C\right)\left(R_{P R O}\right)+I C\left(R_{M A R}\right)
\end{array}\right.
$$

If there exists several implementation system schemes of e-commence, the total information content of each execution system can be expressed as:

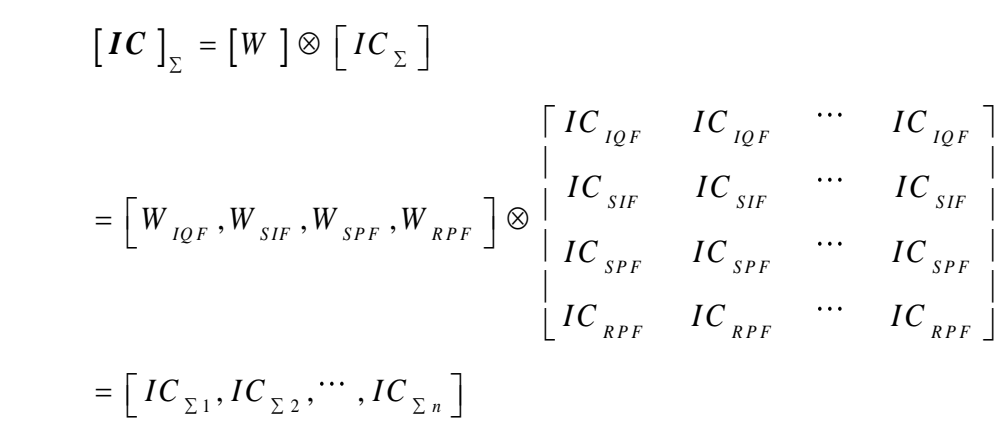

In system decision making of e-commence, the best system is that with the smallest information content. 


\section{Application Example}

This paper takes analysis of an e-commence system of a certain business for the implementation of verification. Via questionnaire analysis and specialist consultation, the corresponding implementation factors in e-commence, evaluation index, weight of evaluation index and corresponding parameter values, as presented in Table 1.

According to the calculation model and algorithm of implementation factors in ecommence, corresponding information content can be obtained, as shown in Table 2. It needs to be noted that IIC represents information content of index, and CIC represents comprehensive information content.

Thus comprehensive information content sequence of e-commence systems could be obtained, namely $I C=\left(I C_{\Sigma 1}, I C_{\Sigma 2}, I C_{\Sigma 3}\right)=(0.1202,0.1211,0.1361)$. It can be observed that the ecommence system 1 contains the least information content, so it is the best system among the given candidates. The consequence of the identification consists with the practical operation performance of e-commence systems, which proye the feasibility and validity of the algorithm and the model built in the paper.

Table 1. Implementation Factors and Evaluation System Parameters

\begin{tabular}{|c|c|c|c|c|c|c|}
\hline \multirow{2}{*}{$\begin{array}{l}\text { Implementation } \\
\text { factors }\end{array}$} & \multirow{2}{*}{ Weight } & \multirow{2}{*}{$\begin{array}{l}\text { Evaluation } \\
\text { index }\end{array}$} & & \multicolumn{3}{|c|}{ Value of the factor } \\
\hline & & & weignt & System 1 & System 2 & System 3 \\
\hline \multirow{4}{*}{$\begin{array}{l}\text { Information } \\
\text { quality }\end{array}$} & \multirow{4}{*}{0.20} & Integrity & 0.25 & 0.90 & 0.93 & 0.95 \\
\hline & & Relativity & 0.25 & 0.95 & 0.90 & 0.85 \\
\hline & & Timeliness & 0.25 & 0.93 & 0.90 & 0.92 \\
\hline & & Volune & 0.25 & 0.90 & 0.95 & 0.90 \\
\hline \multirow{4}{*}{$\begin{array}{c}\text { System } \\
\text { implementation }\end{array}$} & \multirow{4}{*}{0.25} & Reliability & 0.25 & 0.93 & 0.90 & 0.92 \\
\hline & & Sensitivity & 0.25 & 0.90 & 0.85 & 0.93 \\
\hline & & & 0,25 & 0.95 & 0.90 & 0.92 \\
\hline & & Security & 0.25 & 0.95 & 0.92 & 0.90 \\
\hline \multirow{3}{*}{$\begin{array}{c}\text { Service } \\
\text { performance }\end{array}$} & & & 0.40 & 0.90 & 0.93 & 0.85 \\
\hline & & & 0.20 & 0.92 & 0.85 & 0.90 \\
\hline & & & 0.40 & 0.95 & 0.90 & 0.92 \\
\hline \multirow{4}{*}{$\begin{array}{c}\text { Revenue } \\
\text { performance }\end{array}$} & & Popularity & 0.20 & 0.92 & 0.95 & 0.93 \\
\hline & & Cost & 0.20 & 0.005 & 0.007 & 0.005 \\
\hline & & Profit & 0.30 & 0.90 & 0.92 & 0.90 \\
\hline & & $\begin{array}{l}\text { Market } \\
\text { prospect }\end{array}$ & 0.30 & 0.85 & 0.92 & 0.85 \\
\hline
\end{tabular}

Table 2. Information Content of Evaluation Index

\begin{tabular}{cccccccc}
\hline \multirow{2}{*}{$\begin{array}{c}\text { Evaluation } \\
\text { indementation }\end{array}$} & \multicolumn{2}{c}{ System 1 } & \multicolumn{2}{c}{ System 2 } & \multicolumn{2}{c}{ System 3 } \\
\cline { 3 - 8 } & Completeness & IIC & CIC & IIC & CIC & IIC & CIC \\
\hline \multirow{3}{*}{ Information quality } & Relativity & 0.072 & & 0.101 & & 0.072 & \\
& Timeliness & 0.101 & 0.023 & 0.144 & 0.023 & 0.216 & 0.027 \\
& Volume & 0.144 & & 0.144 & & 0.115 & 0.072 \\
& Reliability & 0.101 & & 0.144 & & 0.144 & \\
\hline \multirow{3}{*}{ System } & Sensitivity & 0.144 & 0.024 & 0.216 & 0.039 & 0.101 & \\
implementation & Integrity & 0.072 & 0.024 & 0.144 & & 0.115 & 0.030 \\
& Safety & 0.072 & & 0.115 & & 0.144 & \\
\hline
\end{tabular}




\begin{tabular}{lcllllll}
\hline \multirow{3}{*}{ Service performance } & Service rate & 0.144 & & 0.101 & & 0.216 & \\
& Service mode & 0.115 & 0.022 & 0.216 & 0.028 & 0.144 & 0.032 \\
& Service attitude & 0.072 & & 0.144 & & 0.115 & \\
\hline & Popularity & 0.115 & & 0.072 & & 0.101 & \\
Revenue performance & Cost & 0.072 & \multirow{2}{*}{0.051} & 0.101 & 0.031 & 0.072 & \multirow{2}{*}{0.047} \\
& Profit & 0.144 & & 0.115 & & 0.144 & \\
& Market prospect & 0.216 & & 0.115 & & 0.216 & \\
\hline
\end{tabular}

\section{Conclusion}

Aiming at the complexity of implementation factors in e-commence system and multiple attributes of evaluation index system, this paper puts forward an information context measurement model that can improve implementation factors in e-commence. This model firstly analyzes the implementation factors of e-commence systems then determines information quality, system performance, service performance and revenue performance as the evaluation index. On the basis of information axiom, corresponding computational methods of information content meâsurement aiming at different evaluation indexes are established. Under the condition that considering weigh of different indexes and implementation factors, the comprehensive information content model of e-commence system is built. By the instance analysis, finally the feasibility and effectiveness of the model in this study is proved.

\section{Acknowledgments}

This work is supported by National atural Science foundation of China (51178053) and Natural Science Foundation ofChongqing (cstc2013jcyjA30015).

\section{References}

[1] T. Davis, "E-commerce Measurements and Analysis", Statistics Journal of the United Nations Economics Commission for Europe, vol 20, no. 3, (2003), pp. 289-301.

[2] S. Kumar and P. Petersen, "Impact of E-ecommerce in Lowering Operational Costs and Raising Customer Satisfaction”, Jounal of Manufacturing Technology Management, vol. 17, no. 3, (2006), pp. 283-302.

[3] P. Huang, N.H. Lurie and S. Mitra, Searching for Experience on the Web: An Empirical Examination of Consumer Behav or for Search and Experiences Goods", Journal of Marketing, vol. 73, (2009), pp. 55-69.

[4] W.H. Delone and E. R. Mclean, "Information Systems Success: The Quest for the Dependent Variable", Information Systems Research, vol. 3, no. 1, (1992), pp. 60-95.

[5] W.H. Delone and E. R. Mccean, "The Delone and Mclean Model of Information Systems Success: A Ten-Year Update”, Journal of Management Information Systems, vol. 19, no. 4, (2003), pp. 9-30.

[6] W.H. Delone and E. R. Mclean, "Measuring e-commerce success: Applying the Delone \& Mclean Information Systems Success Model”, International Journal of Electronic Commerce, vol. 9, no. 1, (2004), pp. 31-47.

[7] P. B. Seddon "A Respecification and Extension of the Delone and Mclean Model of IS Success", Information Systems Research, vol. 8, no. 3, (1997), pp. 240-253.

[8] P. B. Sedaion and M. Y. Kiew, "A Partial Test and Development of the Delone and McLean Model of IS Success", Australasian Journal of Information Systems, vol. 4, no. 1, (1996), pp. 90-109.

[9] J. H. Wu and Y. M. Wang, "Measuring KMS Success: A Respecification of the DeLone and McLean's Model”, Information \& Management, vol. 43, no. 6, (2006), pp. 728-739.

[10] O. Madara, "Conceptual Design Using Axiomatic Design in a TRIZ Framework", Procedia Engineering, vol. 9, (2011), pp. 736-744.

[11] D. L. Kwangduk, N.P. Suh and H. O. Jae, “Axiomatic Design of Machine Control System”, CIRP Annals Manufacturing Technology, vol. 50, no. 1, (2001), pp. 109-114.

[12] O. Kulak, M. B. Durmuşoğlu and C. Kahraman, "Fuzzy Multi-Attribute Equipment Selection Based on Information Axiom”, Journal of Materials Processing Technology, vol. 169, no. 3, (2005), pp. 337-345.

[13] N.P. Suh and S. H. Do, "Axiomatic Design of Software Systems", CIRP Annals - Manufacturing Technology, vol. 49, no. 1, (2000), pp. 95-100. 


\section{Authors}

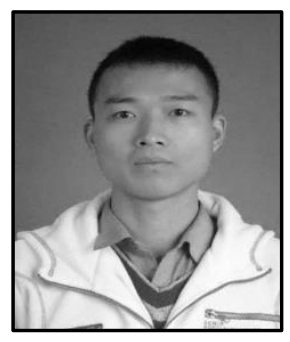

Peng Jinshuan received his $\mathrm{Ph}$.D. in vehicle operation engineering (2012) from Chang'an university. Now he is an assistant professor of transportation, Chongqing Jiaotong University. His current research interests include driving behavior and E-commerce implementation evaluation.

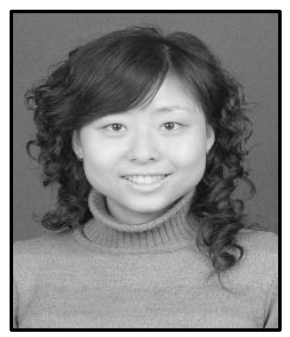

Xu Lei received her Ph.D. in logistic engineering (201) from Chang'an university. Now she is an assistant professon of traffic management, Chongqing Jiaotong University. Her current research interests include E-commerce implementation evaluation and supply chain emergency management.

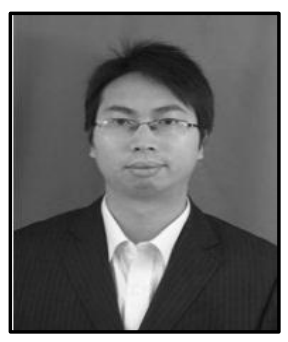

Zhou Xiaoxiang received his haster degree in logistic management (2011) from China University of Mining Technology. Now he is an assistant profes 80 of logistics management, Chongqing Jiaotong University. His currents research interests include logistics system evaluation and human resource management.

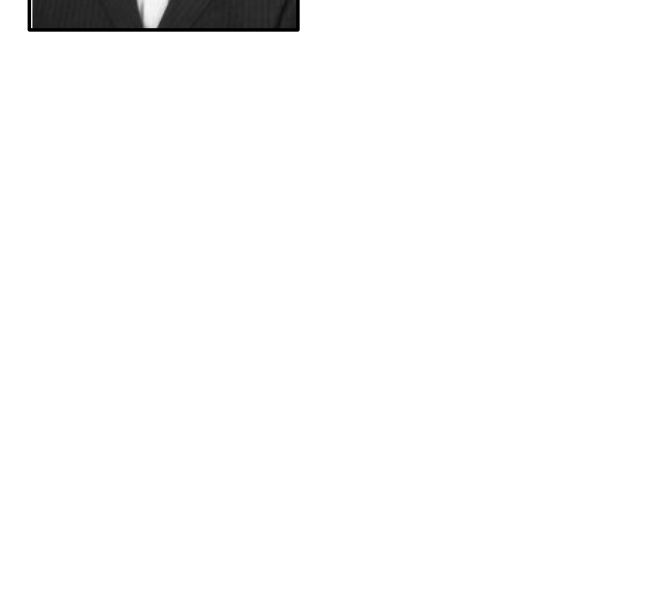

